The new generation Iraqi neurosurgeons' armamentarium to gain the Nobel Prize, an overview of the planning and expectation for the future 


\title{
The new generation Iraqi neurosurgeons' armamentarium to gain the Nobel Prize, an overview of the planning and expectation for the future
}

\author{
Samer S. Hoz ${ }^{1}$, Mohammed Maan Abdul Azeez ${ }^{2}$, Ali Adnan \\ Dolachee $^{3}$, Osama M. Al-Awadi ${ }^{4}$, Luis Rafael Moscote-Salazar ${ }^{5}$ \\ ${ }^{1}$ Neurosurgeon, Neurosurgery Department, Neurosurgery Teaching Hospital, Baghdad, IRAQ \\ ${ }^{2}$ Medical student, College of Medicine, Baghdad University, IRAQ \\ ${ }^{3}$ Neurosurgeon, Department of Neurosurgery, College of Medicine, Al-Qadisiyah University, \\ IRAQ \\ ${ }^{4}$ Neurosurgeon, Neurosurgery Department, Nursing-Home Hospital, Baghdad, IRAQ, President \\ of the Association of Neurological Surgeons in IRAQ \\ ${ }^{5}$ Neurosurgeon, Cartagena Neurotrauma Research Group, Universidad de Cartagena, Cartagena, \\ COLOMBIA
}

\section{Introduction}

Nobel Prizes are among the most famous and most prominent scientific awards worldwide (1). Since the first Nobel Prizes were awarded in 1901, the recipients have captured the interest of the world's scientific, literary, and political communities (2).

The four science Nobel prizes (physics, chemistry, medicine/physiology, and - since 1969 - economics) have performed extremely well as a method of recognizing the highest level of achievement (3). The Nobel Prize in Physiology or Medicine is closely related to human diseases, for which it is paid more attention (4).

Although originally awarded to individuals, the science prizes are now awarded a maximum of once a year to a maximum of three laureates, which makes a maximum total of only 12 laureates annually (3). No one has so far won the Nobel Prize in Physiology or Medicine twice in a lifetime (4).

The average intelligence quotient (IQ) in Iraq is 87 which represents the 20th of the world ranking (5) which is as an average will be the best starting point for astonishing future. Richard Lynn and Tatu Vanhanen argue that differences in national income are correlated with differences in the average national IQ. These results are controversial and have caused much debate, they must be interpreted with extreme caution (5).

Every now and then it is important to update and, if necessary, adjust our ways of operationalizing and valuing excellence (6). It would be useful in developing new algorithms for guiding the individual's and the 
community's contribution to science (7). By singling out individual scientists as paragons of scientific achievement in their fields, the Nobel Prize seems to endorse the "archetypical" idea of a solitary researcher making his or her one great discovery or invention, to the benefit of mankind, as it is stated in Alfred Nobel's will (6).

Analyzing citation impact, it was shown by Bornmann and Leydesdorff that countries such as USA, U.K., and Germany, having a high population number and a well-working economy, lead in science $(8,9)$. When exploring biographical and historical accounts of these communities, it was apparent that much greater interconnectedness existed among scientific communities than is reflected by doctoral mentor-mentee relationships (7).
In short, science in the Big Science era has become an activity that is more complicated even than playing simultaneous chess. It might be compared to playing a variety of different games on different boards simultaneously, with each game having its own standards of excellence, its own morale (6).

\section{Planning discussion}

Five levels are the ladder to the doctor in general (and for the neurosurgeon in specific) to be a world-class scientist and then will be ready for the competition on Nobel Prize nomination. These are 1. Personal level. 2. Local institution level. 3. National level. 4. International level. 5. World-class level (Figure 1).

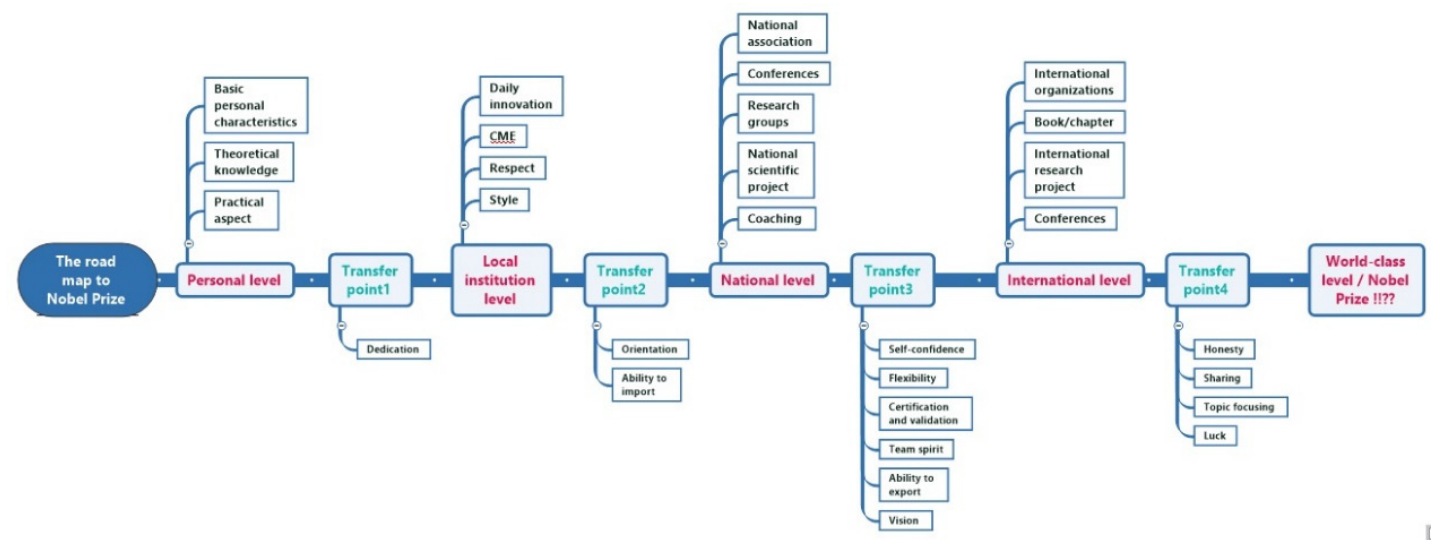

Figure 1 - New generation Iraqi neurosurgeons' armamentarium to gain the Nobel Prize (levels and transfer points requirements)

\section{Level 1}

The personal level focuses on the basic individual characteristics, theoretical knowledge and the practical aspect. The basic personal characteristics which include 2 main elements a. The Knowledge and passion for learning anatomy and/or Physiology and/or radiology. b. technical skills required for surgery in general.

These characteristics should be as perfect as possible and it will determine future direction based on your confidence in them. 
The theoretical knowledge of neurosurgery requires a thorough studying of different resources (textbooks, notes and cases books, Q and A books, websites, YouTube channels and even mobile applications). The studying of these resources must be in 3 ways, the first is a general appreciation of the topics then you must read them focusing on the exam style requirements and the final way is to read the topics with an interest-oriented way (i.e.: focusing on the topics you are more interested in to build up ideas and to comprehend the defect in the current literature for future directions).

The personal level should include focusing on the practical side and to spend as much time as possible in the operation room whether observing or scrubbing as that will improve your personal abilities to be more patient, delicate and oriented during surgery, that's why the operations record is always important and represents a critical point in the curriculum vitae of any neurosurgeon.

Transfer point 1 (from the personal level to the local institute level):

The dedication and appreciation of your job is the only requirement to get access to the next level. You can't be distinguished from your coworkers unless you have an extradedication and passion for your daily job as compared with your colleagues.

\section{Level 2}

The local institute (hospital or college): four ideas should be delivered and enhanced during your daily work in your institution to fulfill this level, these include 1 . Show respect to every person in your institute, happily obey your up-line commands and always try participate in an active team work. 2. Active participation in all the CME (continuous medical education) events and with the time make an effort to suggest new directions or new events to force yourself for continuous studying and being oriented about the updates in your field. 3. Try to add new innovative points in each of the usual daily activities in your work even the simple one like patient examination or preparation for surgery or medical records. 4 . Try to build up your own style as a surgeon, this requires an equilibrium between being different and being safe surgeon.

Transfer point2 (from the local institution level to the national level):

Two critical requirements for this transfer, being a really oriented person (oriented about your job) and the ability to import an international ideas or activities or projects into your country.

\section{Level 3}

National level: five phases needed to do a recognized activity at the national level, these include: 1. Attending, active participation and even organizing conferences at the national level. 2. Arrange research groups to conduct multi-center or national studies. 3. Participate and support the national association or society. 4. Start new national scientific project fundamentally created to fit your country needs. 5. Coaching younger colleagues and even medical students interested in Neurosurgery and support them as much as possible as they will be your team in the future or they may be the next Nobel laureates. 


\section{Transfer point 3: (from national level to the international level)}

Six points desired for this transfer, 1 . Selfconfidence. 2. Flexibility in the method of thinking, in the ideas and even in the lifestyle. 3. Certification and validation of your previous work. 4. A real team spirit and work. 5. Ability to export your national and local experience or projects to the international scientific community. 6. Finally and the most important is to have the vision and expectations of the next steps for the upcoming future.

\section{Level 4}

The international level: 4 stages should be optimized to reach this level: 1 . Attending of international conferences, workshops and even online conferences as a participant and then as a speaker to present your work and the current status of neurosurgery in your institution or country. 2. Participate or start an international research project. 3. Participate in an international book chapter or even write your own. 4. Be in contact with the international organizations, societies or association and try to be involved in their projects to be a dynamic fellow and then a member of their international authorities.

All these will support your chances to build your personal relationships and to enrich your scientific social network which is the foremost goal not only a way to promote your career at that esteemed level.

Transfer point 4: (from the international level to the world-class level)

Four imperative facets are useful here, 1. Honesty with yourself, your patients and your colleagues is a huge step that builds up people trust and pushes you toward your target. 2 . Having the ability to invent ideas, projects and achievements sharing will maximize your productivity. 3. A particular topic directing (like your real interest in a specific disease) during the whole carrier will increase your opportunity to invent a new idea, treatment option or surgical technique about it. 4 . Finally, the luck in choosing opportunities will have a great impact on your global influence.

Obtaining Nobel awards clearly constitutes a crucial challenge for nations worldwide, as they are a significant determinant of a country's prestige and a reliable index of the efficiency of its scientific policy (1). Still, for many scientists, it is difficult to imagine that virtual proximity could ever be a satisfying replacement for the day-to-day personal interaction found in a positive mentoring relationship (7).

Acknowledgement should stay as our basic desire, fueling creativity and perseverance, even under hazardous conditions, and science continues to rely on individuals who are willing to display this behavior (6).

Nobel awards are central indicator of a country's scientific achievement, which includes the number of publications and research expenditure (1), so having the vision and the insightful thinking will promote the next generation Iraqi neurosurgeon to attain more recognized position and high qualification and that may render them as future nominees for the Nobel Prize. 


\section{References}

1.Doi H, Heeren A, Maurage P (2014) Scientific Activity Is a Better Predictor of Nobel Award Chances than Dietary Habits and Economic Factors. PLoS ONE 9(3): e92612.

2.Lichtman MA. Alfred Nobel and His Prizes: From Dynamite to DNA. Rambam Maimonides Med J 2017;8 (3):e0035. Review. doi:10.5041/RMMJ.10311

3.Charlton B. Why there should be more science Nobel prizes and laureates - And why proportionate credit should be awarded to institutions. Medical Hypotheses. 2007;68(3):471-473.

4.Ye S, Xing R, Liu J, Xing F. Bibliometric analysis of Nobelists' awards and landmark papers in physiology or medicine during 1983 2012. Annals of Medicine. 2013;45(8):532-538.

5.Davies C. IQ AND GLOBAL INEQUALITY - by Richard Lynn and Tatu Vanhanen. Economic Affairs. 2007;27(3):104-105.
6.Zwart H. The Nobel Prize as a Reward Mechanism in the Genomics Era: Anonymous Researchers, Visible Managers and the Ethics of Excellence. Journal of Bioethical Inquiry. 2010;7(3):299-312.

7.Chariker J, Zhang Y, Pani J, Rouchka E. Identification of successful mentoring communities using networkbased analysis of mentor-mentee relationships across Nobel laureates. Scientometrics. 2017;111(3):1733-1749. 8.Bornmann L, Leydesdorff $\mathrm{L}$. The validation of (advanced) bibliometric indicators through peer assessments: A comparative study using data from InCites and F1000. Journal of Informetrics. 2013;7(2):286-291.

9.Schlagberger E, Bornmann L, Bauer J. At what institutions did Nobel laureates do their prize-winning work? An analysis of biographical information on Nobel laureates from 1994 to 2014. Scientometrics. 2016;109(2):723-767. 